\title{
Distal radyoulnar eklem sorunlarında kurtarıcı cerrahi işlemler
}

\author{
Salvage surgery for distal radioulnar joint disorders
}

\author{
Osman Orman, Ayberk Önal \\ Sağlık Bilimleri Üniversitesi, Metin Sabancı Baltalimanı Kemik Hastalıkları Eğitim ve Araştırma Hastanesi, \\ El Cerrahisi Kliniği, İstanbul
}

Distal radyoulnar (DRU) eklemde instabiliteyle beraber artroz olması tedaviyi zorlaştırır. DRU eklem problemi düzeltilemiyor ve yumuşak doku dengesi sağlanamıyorsa kurtarıcı (salvage) cerrahi prosedürler uygulanması gerekir. Kurtarıcı tedavilerde amaç azami el bileği hareket açıklığının ağrısız şekilde tekrar kazanılmasıdır. DRU eklemin anatomisini en az değiştiren işlemden en çok değiştiren işleme, kurtarıcı cerrahiler: Distal ulna hemirezeksiyonları (Bower, Watson), Sauvé-Kapandji cerrahisi, Darrach cerrahisi ve tek kemikli ön kol cerrahisidir. Distal ulna hemirezeksiyonu; ulna eklem yüzünün kısmi olarak çıkarılmasıdır, bu işlem planlanan hastalarda radius ve ulnada deformite olmamalıdır. Sauvé-Kapandji cerrahisi; ulna başının radiusa füzyonu ve ulnada psödo-artroz oluşturma işlemidir, radiusda deformitesi olmayan veya düzeltilebilir deformitesi olan hastalarda ve erken dönem romatoid artritte önerilir. Darrach cerrahisi; distal ulnanın tamamen çıkarılmasıdır, radiusta düzeltilemeyen deformitesi olan sedanter hastalarda ve ileri romatoid artritte uygulanabilir. Tek kemikli ön kol cerrahisi; ulna ve radiusun birbirine kaynatılarak ön kolu tek kemikten oluşur hale getirmektir. Bu cerrahi sonrası ön kol rotasyonu tamamen kısıtlanır. Diğer kurtarıcı işlemlerin uygulanamadığı veya başarısız olduğu durumlarda kullanılan en son seçenek cerrahisidir.

Anahtar sözcükler: Darrach; distal ulna hemirezeksiyon interpozisyon artroplastisi; Sauvé-Kapandji; tek kemikli ön kol
Instability associated with arthritis of the distal radioulnar (DRU) joint is a challenging problem to solve. If bone deformity in the forearm cannot be corrected and soft tissue balance cannot be achieved, salvage procedures could be performed. In salvage surgeries for DRU joint, the aim is to regain pain free, maximal range of motion at the wrist. Salvage surgeries that change the anat-omy of the DRU joint at least to the most, are: Distal ulna hemi-resections (Bower, Watson), Sauvé-Kapandji surgery, Darrach surgery and one bone forearm surgery. Distal ulna hemi-resection; is partial removal of the ulna joint. This procedure should not plan if there are deformities in the radius and ulna. Sauvé-Kapandji surgery; is the fusion of the ulna head to the radius and the process of creating pseudoarthrosis in the ulna. It is preferred for early rheumatoid arthritis and patients with no or correctable deformity in the radius. Darrach surgery; is removal of the distal ulna. It can be applied in sedentary and advanced rheumatoid arthritis patients and patients with noncorrectable deformity in the radius. One bone forearm surgery; is fusion of ulna and radius to make the forearm consist of a single bone. Forearm rotation is totally restricted after this surgery. It is the final surgery where other salvage procedures could not be performed or failed.

Key words: Darrach; distal ulna hemi-resection arthroplasty; Sauvé-Kapandji; one bone forearm

- Dejeneratif veya travmatik DRU eklem artriti ve instabilitesi

- Romatoid artrit

- Diğer sorunlar; konjenital sorunlar, tümör

Distal radyoulnar eklem instabilitesinin eşlik etmediği osteoartritte; ulna eklem yüzünün kısmi olarak

- Illetişim adresi: Op. Dr. Osman Orman, Baltalimanı, Balta Limanı Hisar Cd. No: 62, 34470 Sarıyer, İstanbul

Tel: 0532 - 6553633 e-posta:osmanorman@gmail.com

- Geliş tarihi: 1 Mayıs $2021 \quad$ Kabul tarihi: 8 Mayıs 2021

ORCID iD: Osman Orman, 0000-0002-9177-2457 • Ayberk Önal, 0000-0002-7837-0058 

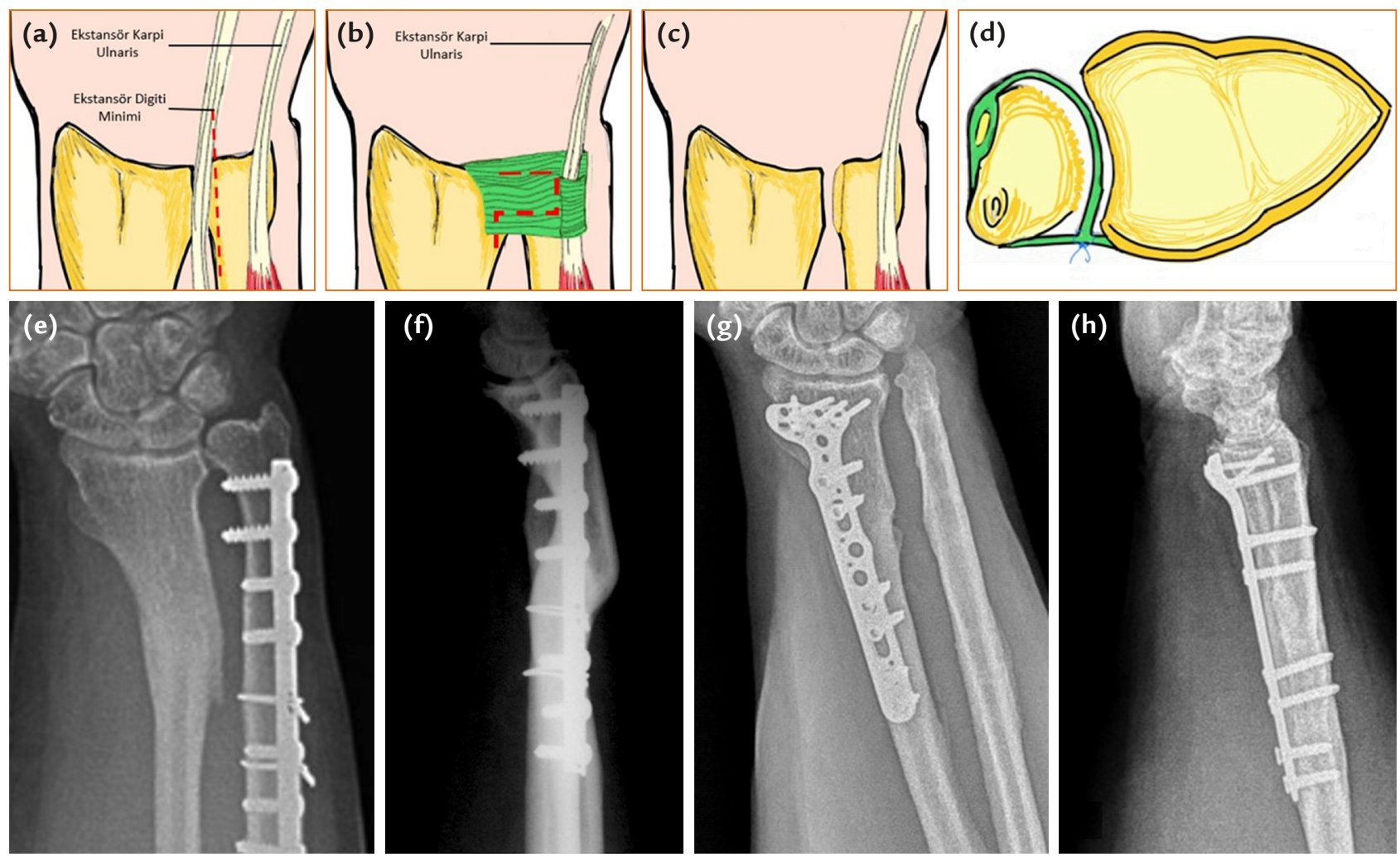

Şekil 1. a-h. Distal ulnar hemirezeksiyon: Distal radyoulnar eklem üzeri uzunlamasına cilt kesisi (a). Dorsal radyoulnar eklem kapsülünün dikdörtgen şeklinde radyal bazlı olarak kaldırılması (b). Ulna başının, ulna boynuyla aynı hizaya getirilmesi (c). Dorsal radyoulnar kapsülün volar radyoulnar kapsüle dikilmesi (d). Radiusda açı ve kısalık deformitesi olan olgunun ameliyat öncesi ve sonrası postero-anterior (PA, arka-ön) ve lateral (yan) grafileri (e, f). Aynı hastanın ameliyat sonrası PA ve lateral grafileri, radiusa düzeltici osteotomi ve tespite ek olarak distal ulnar hemirezeksiyon uygulanmış (g, h). (Dr. Kahraman Öztürk'ün arşivinden izni ile alınmıştır)

çıkarıldığı distal ulna hemirezeksiyon interpozisyon artroplastisi, DRU eklem osteoartriti ve erken dönem romatoid artritte de uygulanabilen ulna başının radiusa füzyonu ve ulnada psödoartroz oluşturma işlemi Sauvé-Kapandji cerrahisi, sedanter hastalarda ve ileri romatoid artritte uygulanan distal ulnanın $3 \mathrm{~cm}$ çıkarıldığı Darrach cerrahisi yapılabilir. Tek kemikli ön kol cerrahisi; ulna ve radiusun birbirine kaynatılarak ön kolu tek kemikten oluşur hale getirmektir. Bu cerrahi sonrası ön kol rotasyonu tamamen kısıtlanır. Diğer kurtarıcı işlemlerin uygulanamadığı veya başarısız olduğu durumlarda kullanılan en son seçenek cerrahisidir. ${ }^{[1,2]} \mathrm{Bu}$ tedavilere, uygulandığı küçük gruplarda başarılı sonuçlar elde edilen DRU eklem artroplastileri de eklenebilir. ${ }^{[1]}$

\section{DISTAL ULNA HEMIREZEKSIYON ARTROPLASTI AMELIYATI (BOWER'IN CERRAHISI)}

Triangular fibrokartilaj kompleksin (TFKK) ulnaya yapıştı̆̆ı bölümlerin korunarak ulnanın DRU eklem yüzünün çıkarılma cerrahisidir. ${ }^{[3-5]}$

\section{Endikasyonları}

- Radius ve ulna deformitesinin eşlik etmediği, TFKK'nin sağlam olduğu DRU eklem instabilitesi ve/veya osteoartriti.

\section{Cerrahi Teknik}

Distal radyoulnar eklem üzeri, 5. ve 6. ekstansör kompartmanlar arasından $5 \mathrm{~cm}$ uzunlamasına kesiyle başlanır. Ekstansör dijiti minimi (EDM) tendon kılıfı açılarak içinden geçilir. DRU eklem kapsülüne ulaşılır. Eklem kapsülü ulna bazlı dikdörtgen flep olarak kaldırılır. Bu flebin alt kenarı ulna boynu, üst kenarıysa ulna stiloidi hizasıdır. Bu flebin kaldırılması sırasında TFKK ve ekstansör karpi ulnaris (EKU) tendon kılıfı korunmalıdır. DRU eklem açıldıktan sonra ulna başı, ulna boynuyla aynı hizaya gelecek şekilde inceltilir. Ulna distali de TFKK korunarak bir miktar tıraşlanabilir. Dorsalden dikdörtgen şeklinde kaldırılan eklem kapsül flebi volar DRU eklem kapsülüne dikilir (Şekil 1). Bir başka seçenekse tendon veya kastan yapılan ançüezin oluşan boşluğa yerleştirilerek kapsülün kapatılmasıdır. ${ }^{[4,5]}$ 


\section{Cerrahi Sonrası}

íki hafta boyunca dirsek altı atel uygulanır. Bu süre boyunca parmak hareketlerine izin verilir, ön kol rotasyonu zorlamadan serbest bırakılır. íki hafta sonra atel sonlandırılır.

\section{Komplikasyonlar}

- Stilokarpal sıkışma: Ulna stiloidi uzun kalarak trikuetruma temas edebilir. Bu teması önlemek için cerrahi planlama sırasında ulna varyansı göz önünde bulundurulmalıdır. Cerrahi sırasında ya da cerrahi sonrası sıkışma gelişen olgularda ulna stiloidine kısaltma uygulanabilir.

- Ulnokarpal sıkışma: Ulna distalinin karpal kemiklere sürtünmesidir. Bu sorun pozitif ulnar varyans sorununun çözülmediği olgularda gelişir. Cerrahi sırasında ya da cerrahi sonrası sıkışma gelişen olgularda ulnaya kısaltma uygulanabilir.

\section{RADIUSA EŞLENMIŞ (MATCHED) DISTAL ULNA REZEKSIYONU}

Distal 5-6 cm ulna bölümünün tıraşlanarak, radiusla takılma veya sürtünme olmayacak şekilde rotasyon yapacak hale getirilmesidir. Bu işlem sırasında yumuşak doku transpozisyonu yapılmaz. Ulna stiloidi işlem sırasında eksize edilebilir. ${ }^{[3,6,7]}$

\section{Cerrahi Endikasyonlar}

Distal ulna hemirezeksiyonuna benzerdir.

\section{Cerrahi Teknik}

Distal ulna hemirezeksiyonuna benzer şekilde DRU eklem üzerinden yapılan insizyonla girilir. Dorsal DRU eklem kapsülü uzunlamasına açılır. Ulnanın 5-6 $\mathrm{cm}$ distali kalem ucuna benzer şekilde tıraşlanarak radiusla olan sürtünme ortadan kaldırılır. Bu işlem sırasında ulna stiloidi de tıraşlanabilir. TFKK zamanla EKU kılıfına ve açıkta bırakılan süngerimsi kemiğe kendiliğinden yapışır. Eklem kapsülü onarılarak operasyon sonlandırılır (Şekil 2).

\section{Cerrahi Sonrası}

Bir hafta dirsek altı atele alınır. Sonrasında tüm hareketler serbest bırakılır.

\section{Komplikasyonlar}

- Cerrahi sırasında radyal taraftaki osteofit oluşumlarının temizlenmemesine veya cerrahi sonrasında oluşan yeni kemik oluşumlarına bağlı radyoulnar sürtünmenin devam etmesidir. Bu kemik oluşumları eksize edilerek tedavi sağlanır.

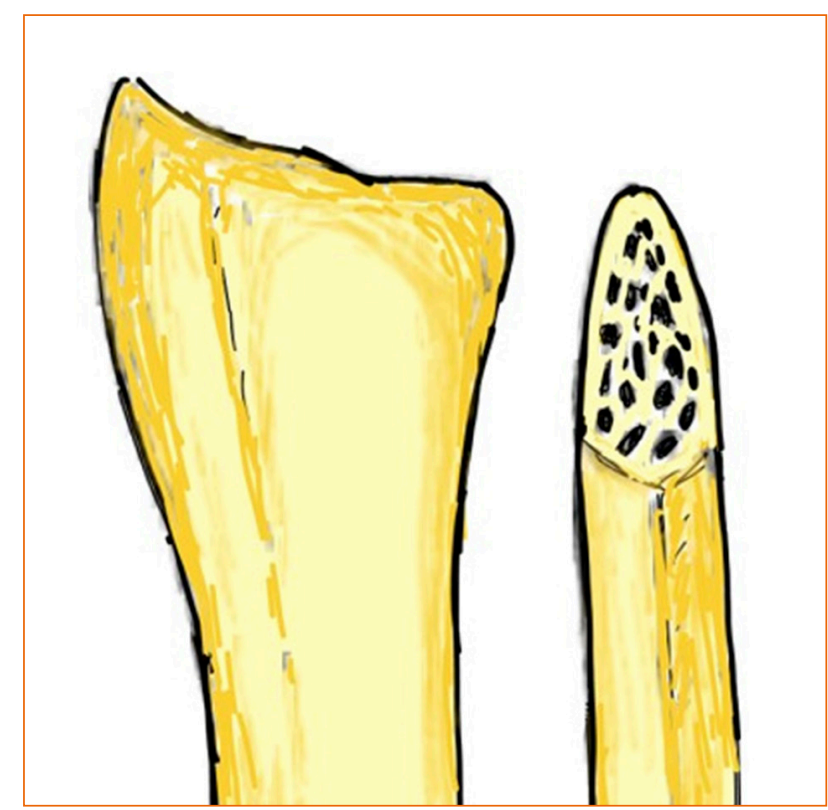

Şekil 2. Radiusa eşlenmiş (matched) distal ulna rezeksiyonu: Distal ulnar hemirezeksiyonunda tariflenen kesileri takiben ulna distaline ulaşılır. Ulnanın 5-6 cm distal kısmı kalem ucu gibi sivrileştirilir.

\section{SAUVÉ-KAPANDJi AMELIYATI}

KIsaca, DRU eklemin artrodezi ve artrodezin proksimalinde ulna psödoartrozu sağlanmasıdır. Oluşturulan psödoartroz ön kol rotasyonunun sağlanması içindir. ${ }^{[3,8-11]}$

\section{Endikasyonları}

- Radius alt uç kırı̆gı sonrası radiusun deformitesi (volar/dorsal açılanma, kısalık)

- DRU eklemin kötü kaynamış kırıkları (sigmoid çentik veya ulna başı kırıkları)

- Madelung deformitesi

- Illeri DRU eklem instabilitesi yaratan radyoulnar bağ yırtıkları ve triangular fibrokartilaj kompleks (TFKK) yırtıkları

- Romatoid artritte DRU eklem erken dönem sinoviti

\section{Cerrahi Teknik}

Sauvé-Kapandji ameliyatı öncesi radiustaki deformite düzeltilmelidir. Tepe noktası sigmoid çentik olan "Kıvrımlı" insizyonla başlanır. Trikuetrum seviyesinde volarden dorsale doğru seyreden ulnar sinir dorsal duyu dalı bulunur ve korunur. Beşinci ekstansör kompartman uzunlamasına açılır ve EDM tendonu ekarte edilir, EKU kılıfı açılmadan korunmaya alınır. DRU 

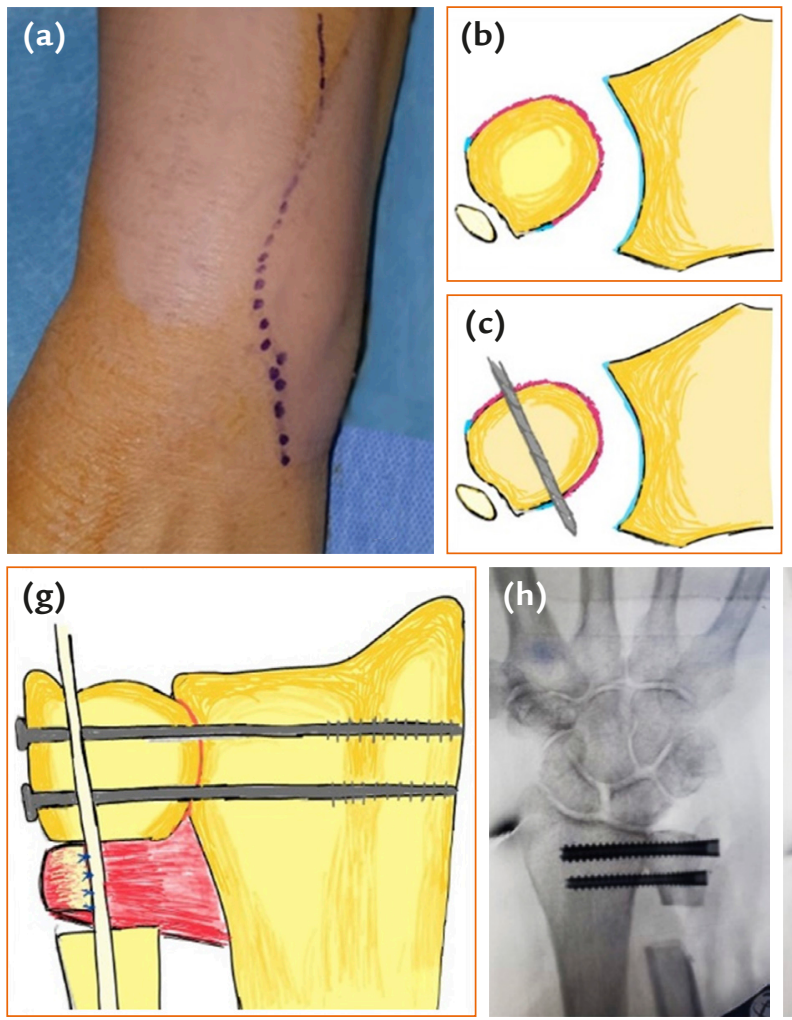
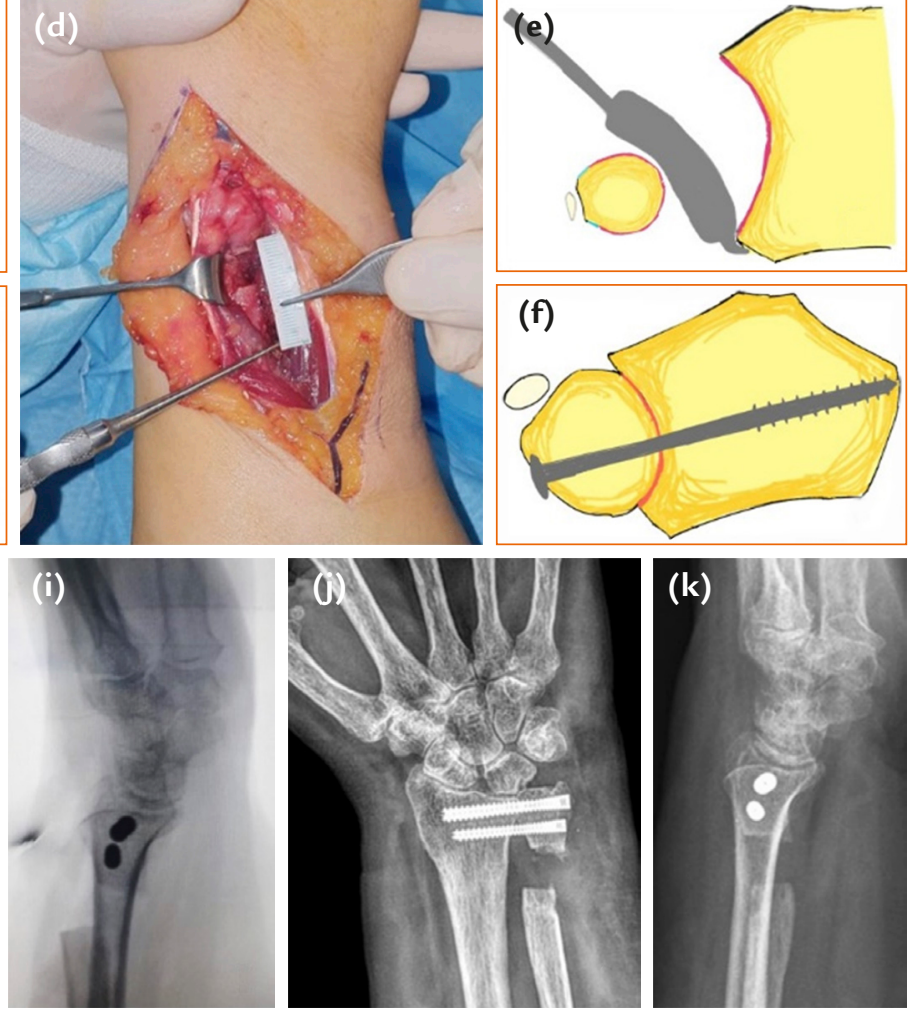

Şekil 3. a-k. Sauve-Kapandji cerrahisi: Distal radyoulnar eklem "Kıvrımlı” cilt kesisi (a). Ulna başı eklem yüzünün tıraşlanması (b). Ulna başının drillenmesi, hemen ekstansör karpi ulnaris ön tarafından girilir (c). Beş ile 10 mm arası ulna kemik fragmanı, distal radyoulnar eklemin proksimalinden eksize edilir (d). Radius sigmoid çentik eklem kıkırdağı tıraşlanır (e). Ulna redükte edilir ve radius, ulnada hazırlanmış delikten drillenir. Kompresyon vidası uygulanır (f). İki adet kompresyon vidası yerleştirilir. Bazı yazarlar pronator kuadratus kasının ekstansör karpi ulnarise dikilmesini önerir (g). Sauve-Kapandji cerrahisi yapılan hastanın ameliyat içi ve sonrası grafileri (h-k).

eklem kapsülü dorsalden radiusa yapışma yerine yakın olacak şekilde uzunlamasına kesilir. Ön kol pronasyona alınarak DRU eklem yüzeylerindeki kıkırdaklar alınır, subkondral kemik ortaya çıkarılır. Subkondral kemik yüzeyleri açığa çıktıktan sonra 3,2 mm drill ile, ulna başı eklem yüzünden kortekse doğru, EKU kılıfı anteriorunda kalacak şekilde, ulna eksenine dik olarak delinir. Aynı drill ulna korteksi taraftan çıkarılarak radiusa doğru, radius eksenine dik olacak şekilde delinir. Sonrasında, DRU eklem kıkırdağının proksimalde bitiş yerinden ulna osteotomize edilir. Osteotomi proksimalinden (nötral ulnar varyansı olan hastalarda) $5 \mathrm{~mm}$ ulna eksize edilir. Ulna pozitif varyansı olan hastalarda bu miktar artırılır. Yarım yivli kortikal vida (malleol vidası veya kompresyon vidası) radius korteksini delmeyecek boyda ölçülerek gönderilir. ${ }^{[12]} \mathrm{Bu}$ vidaya paralel ikinci vida yerleştirilir. Cerrahi sırasında, ulna proksimalinin stabilitesini sağlayan; pronator kuadratus kası, interosseöz membran ve fleksör karpi ulnaris (FKU) hasarlanmamalıdır. Dorsal eklem kapsülü kapatılmaz. El bileği nötral pozisyonda dirsek altı atele alınır (Şekil 3).

\section{Cerrahi Sonrası}

Atel 7-10 gün tutulur, atel içinde supinasyon ve pronasyona izin verilir. Atel çıkarıldıktan sonra kademeli olarak supinasyon ve pronasyon artırılır. Psödoartroz oluşana kadar ağrı olabilir. Ağrısı olan olgularda dinlenme ve steroid olmayan (non-steroid) anti-enflamatuvar ilaçlar önerilir.

\section{Komplikasyonlar}

- Radyoulnar artrodezde kaynamama veya gecikmiş kaynama: Vidanın iyi kompresyon yapmadığı durumlarda gelişir. Cerrahi sırasında yeterli kompresyon sağlanmalıdır. Primer cerrahi sırasında bu bölgeye kemik grefti yerleşimi önerilmez. Kompresyon vida sayısının da iki olması önerilir. Kaynama gelişemeyen olgularda kompresyonu artırmak amacıyla vida değişimine ek olarak kemik grefonaj yapılabilir. ${ }^{[8,13]}$ 
- Psödoartroz bölgesinde fibröz veya osseöz kaynama: Cerrahi sırasında ulnada oluşturulan kemik boşluğu içinde kemik fragman ve periost kalmamasına özen gösterilerek bu sorundan kaçınılabilir. Bu sorun geliştiğinde ikinci bir ameliyatla sorunlu dokunun çıkarılmasıyla tedavi sağlanır. ${ }^{[7]}$

- Proksimal ulnanın ağrılı instabilitesi: Bu sorunu önlemek için ulna kemik defekti hemen ulna başı proksimalinde oluşturulmalı ve bu defektin büyüklüğü $5 \mathrm{~mm}-1 \mathrm{~cm}$ arasında tutulmalıdır. Böylelikle ulna güdüğünün rotasyon merkezi, ön kol rotasyon merkezinden uzaklaşmaz. Ayrıca ulna güdüğüne, el ve el bileği tendonlarınca daha kuvvetli bir destek sağlanır. Bu sorunu önlemek için cerrahi tekniğe bazı modifikasyonlar önerilmiştir: Bunlar kısaca pronator kuadratusun EKU'ya dikilmesi, palmaris longus tendon greftiyle ya da FKUEKU tendonlarından kaldırılan distal bazlı tendon greftleriyle proksimal ulnayı sabitlemektir. ${ }^{[14]}$

\section{DARRACH AMELIYATI}

Darrach ameliyatı farklı modifikasyonları olsa da kısaca ulna distalinin çıkarılmasıdır. Ulna distali subperiosteal eksizyonu, ekstraperiosteal eksizyonu, oblik osteotomi, ulna stiloidinin korunması gibi modifikasyonları da vardır. ${ }^{[15-18]}$

\section{Endikasyonlar}

- Ileri evre romatoid artrit ve kaput ulna sendromu

- Düzeltilemeyen radius kısalığıyla beraber olan ulna başı çıkıkları

- İleri yaş ve düşük beklentili DRU eklem osteoartrit hastaları

- Tümör

\section{Cerrahi Teknik}

Ulna stiloidinden başlayan ve $5-6 \mathrm{~cm}$ proksimale uzayan kesiyle başlanır. Volarden dorsale doğru seyreden ulnar sinir dorsal duyu dalı bulunur ve korunur. EKU tendon kılıfı volarinden ulnaya ulaşııı. Ulnanın distalden 3 cm'lik kısmının periostu kaldırılır. Bu işlem sırasında periosta zarar verilmemeli ve ulna stiloidinin üzerindeki bölümü kaldırılmamalıdır. Hemen sigmoid çentik proksimalinden osteotomi yapılır. Sonrasında ulna stiloidi tabanından osteotomize (transvers veya oblik osteotomi) edilir ve aradaki genellikle $1 \mathrm{~cm}$ büyüklüğündeki kemik fragman çıkarılır. TFKK hasarlı olsa da bu cerrahi sırasında korunmasına özen gösterilmelidir. Ulnanın radiusa temasına sebep olacak translasyonunu ve ulnanın dorsale subluksasyonunu engellemek için pronator kuadratus kası veya EKU tendonu kullanılabilir.
Pronator kuadratus ulna origosundan kaldırılır, distal ulnadan oluşan boşluğa taşınarak ulna güdüğüne sarılır. ${ }^{[17]}$ Diğer bir seçenek olarak EKU ve FKU tendonundan distal bazlı slipler (demetler) kaldırıır. Her iki tendon slipi ulnada hazırlanan kemik tünelden geçirilerek birbirine dikilir. ${ }^{[19]}$ Periost onarıldıktan sonra supinasyon ve pronasyon yaptırılarak ulna ve radius ilişkisi kontrol edilir (Şekil 4).

\section{Cerrahi Sonrası}

Hastalar 3 hafta rotasyonu engelleyen dirsek üstü atelde (şeker maşası ateli) takip edilir.

\section{Komplikasyonlar}

- Ulna güdüğünün stabilitesini kaybederek radiusla sürtünmesi; zorlu bir sorundur. Stabilizasyonu sağlamak için EKU tenodezi (ilk ameliyatta yapılmadiysa), pronator kuadratusun dorsale transferi, radiusla ulnayı geçici pinleme uygulanabilir. Başarısız olgularda hemiartroplasti de bir diğer seçenektir. Tüm bu yöntemlerden yarar görmeyen hastalarda tek seçenek tek kemikli ön kol ameliyatıdır. ${ }^{[18]}$

\section{DISTAL RADYOULNAR EKLEM ARTROPLASTISI}

Distal radyoulnar eklem için hemi (kısmi) ve total artroplastiler mevcuttur. Artroplasti yayınları iyi sonuçlar bildirse de bu çalışmalar küçük olgu serileri ve kısa dönem takiplerden oluşmaktadır. DRU eklem artroplastisi ilgili bölümde anlatılmaktadır. ${ }^{[1]}$

\section{TEK KEMIKLI ÖN KOL AMELIYATI (ONE BONE FOREARM)}

Tek kemikli ön kol ameliyatı DRU eklem artroz ve instabilitesinde nihai tedavidir. Radius ve ulna arası kemik sinostoz ya da "ulnius" oluşturma ameliyatıdır. Ön kol üst uçta ulna ve humerus arası eklem korunurken alt uçta radius ve karpus arası ilişki korunur. Ulnohumeral eklemle radyokarpal eklemler arası tek kemik haline getirilir. ${ }^{[20-22]}$

\section{Endikasyonlar}

- Diğer kurtarıcı işlemlerle düzeltilememiş/düzelme şansı olmayan DRU eklem instabilitesi veya osteoartritine yol açan konjenital deformite, tümör, enfeksiyon ve travma.

\section{Cerrahi Teknik}

Hasta için en uygun ön kol rotasyonu belirlenir. Bunu yaparken hastanın günlük ihtiyaçları, mesleği ve 

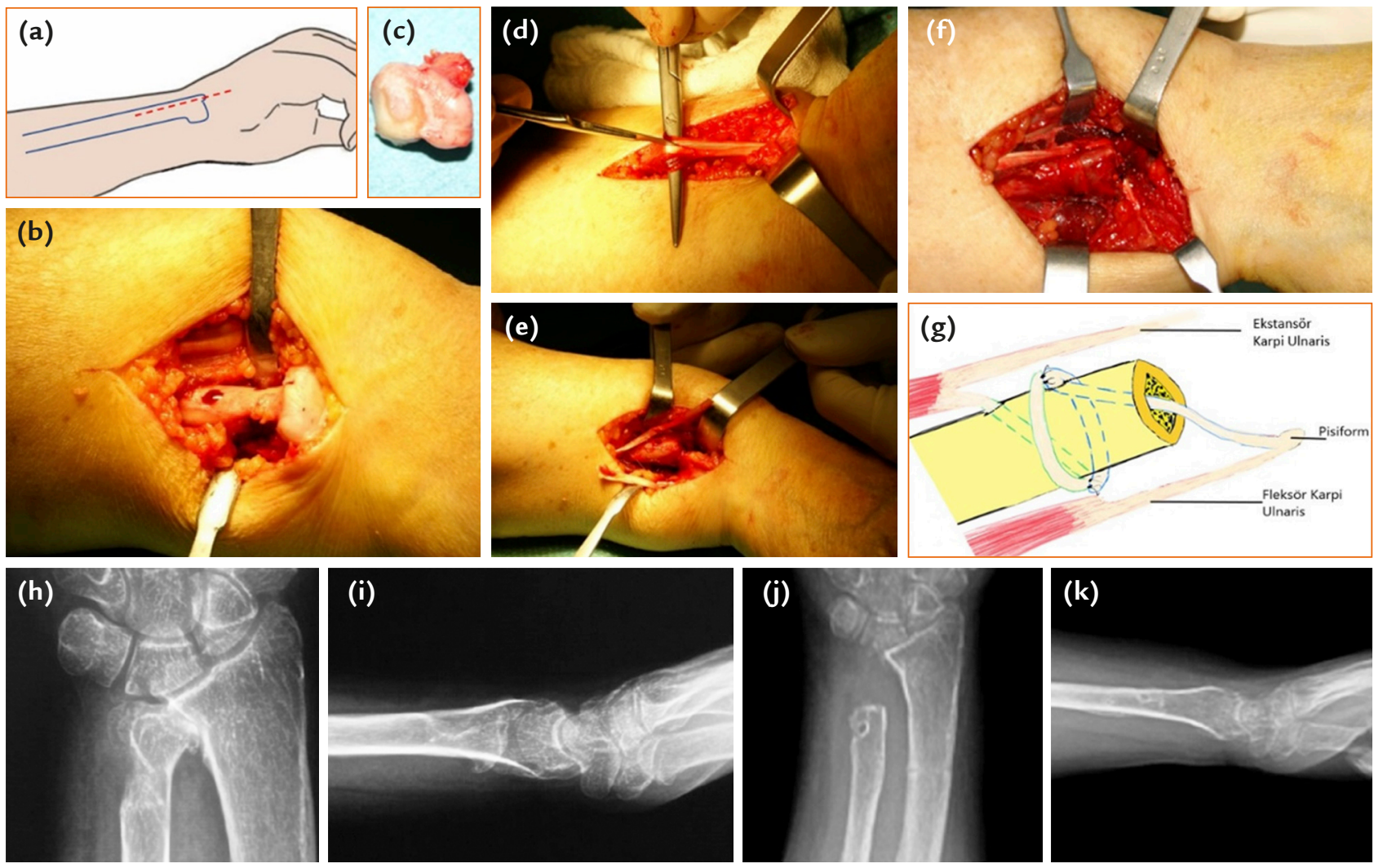

Şekil 4. a-k. Darrach cerrahisi: Ulna stiloid hizasında, dorsolateral uzunlamasına cilt kesisi (a). Periostun keskin disseksiyonla açılarak ulna distaline ulaşılması (b). Ulna distalinin eksizyonu (c). Ekstansör karpi ulnaris ve fleksör karpi ulnaristen kaldırılan distal bazlı tendon şeritleri (d, e). Tendon şeritlerinin ulna proksimalinde hazırlanan kemik tünellerden geçirilerek birbiri üzerine dikilmesinin ameliyat içi ve şematik görüntülemesi $(f, g)$. Distal radyoulnar artroz gelişmiş romatoid artrit hastasının ameliyat öncesi ve sonrası PA (arka-ön) ve lateral (yan) grafileri (h-k). (Dr. Kahraman Öztürk’ün arşivinden izni ile alınmıştır)

diğer kolunun durumu göz önüne alınmalıdır. DRU eklem üzeri ve proksimal radyoulnar eklem (PRU) üzeri iki adet uzunlamasına insizyon yapılır. Distal insizyon, DRU eklem dorsalinden başlar ulna boynunda oblikleşerek ulna lateraline döner. Ulnar sinir dorsal duyu dalı bulunur ve korunur. Beşinci ekstansör kompartman açılır, EDM ekarte edilir. DRU eklem kapsülü açılır. Sigmoid çentikteki eklem yüzleri alınır. Daha önceki ameliyatta ulna başı alınmışsa (Darrach) radius sigmoid çentik karşısı ulna metafizodiyafiziyel kısmı dekortike edilir. PRU eklem üzerinden proksimal ulna dorsal kenarı boyunca uzunlamasına insizyon yapılır. Ankoneus kası ulna lateralinden kaldırılır, radius başına ulaşılır. Anterior eklem kapsülü ve annular bă̆ açılır. Radius başı, radius tuberositasından osteotomize edilir. Ankoneus kası tamamen ulnadan serbestleştirilerek ulna radyal çentiğe ulaşılır. Radyal çentik ve radius metafizi dekortike edilir. Ön kol daha önce belirlenen rotasyon konumuna getirilir. Geçici K-telleri ile konum sabitlenir. Her iki sinostoz alanına kemik greft konulur. Distale ve proksimale ikişer veya üçer adet 2,7 $\mathrm{mm}$ veya $3,5 \mathrm{~mm}$ kortikal vidalar (en az dört korteks geçilecek şekilde) yerleştirilir. ${ }^{[19]}$

Dirsek $90^{\circ}$ fleksiyonda ve el bileği $10^{\circ}$ ekstansiyonda, ayarlanan ön kol rotasyonunda dirsek üstü atele alınır.

\section{Cerrahi Sonrası}

Parmak hareketleri hemen başlanır. Atel iki hafta tutulur. Açı ayarlı dirseklikle fleksiyon ve ekstansiyon hareketleri başlanır. Yaklaşık 6-12 hafta arası kaynama gerçekleşir. Kaynama oluştuktan sonra ortez sonlandırilır ve güçlendirme başlanır.

\section{Komplikasyonlar}

- Kaynamama: Bu sorun özellikle nörofibromatozisli hastalarda konjenital ulna kaynamaması nedeniyle tek kemikli ön kol cerrahisi yapılan hastalarda karşılaşılır. Bu hastalarda kaynama gelişene kadar birden fazla cerrahiye gerek duyulabilir. ${ }^{[23]}$ 
- Yanlış pozisyonlama: Hedeflenen rotasyon konumu baştan hastanın isteğine göre belirlense de sonuç hastanın günlük kullanımında memnuniyetsizlik yaratabilir. Bu sorun cerrahi öncesi geçici ortezlerin hastaya uygulanmasıyla çözülebilir. Hastanın cerrahi sonrası oluşacak durumu önceden gözlemesi ve buna göre karar vermesi sağlanır. ${ }^{[20]}$

\section{KAYNAKLAR}

1. Breyer JM, Vergara P. Solutions for the unstable and arthritic distal radioulnar joint. Hand Clin 2020;36(4):523-30. Crossref

2. Faucher GK, Zimmerman RM, Zimmerman NB. Instability and arthritis of the distal radioulnar joint: A critical analysis review. JBJS Rev 2016;20;4(12):e3. Crossref

3. Lichtman DM, Ganocy TK, Kim DC. The indications for and techniques and outcomes of ablative procedures of the distal ulna. The Darrach resection, hemiresection, matched resection, and Sauvé-Kapandji procedure. Hand Clin 1998;14(2):265-77. Crossref

4. Bowers $W H$. Distal radioulnar joint arthroplasty: the hemiresection interposition technique. J Hand Surg Am 1985;10(2):169-78. Crossref

5. Glowacki KA. Hemiresection arthroplasty of the distal radioulnar joint. Hand Clin 2005;21(4):591-601. Crossref

6. Watson HK, Gabuzda GM. Matched distal ulna resection for posttraumatic disorders of the distal radioulnar joint. J Hand Surg Am 1992;17(4):724-30. Crossref

7. Ahmed SK, Cheung JPY, Fung BKK, Ip WY. Long term results of matched hemiresection interposition arthroplasty for DRUJ arthritis in rheumatoid patients. Hand Surg 2011;16(2):11925. Crossref

8. Kapandji IA. The Kapandji-Sauvé operation: its techniques and indications in non-rheumatoid arthritis. Ann Chir Main 1986;5(3):181-93. Crossref

9. Lluch A. The Sauvé-Kapandji procedure: indications and tips for surgical success. Hand Clin 2010;26(4):559-72. Crossref

10. George MS, Kiefhaber TR, Stern PJ. The Sauvé-Kapandji procedure and the Darrach procedure for distal radio-ulnar joint dysfunction after Colles' fracture. J Hand Surg $\mathrm{Br}$ 2004;29(6):608-13. Crossref

11. Vincent KA, Szabo RM, Agee JM. The Sauvé-Kapandji procedure for reconstruction of the rheumatoid distal radioulnar joint. J Hand Surg Am 1993;18(6):978-83. Crossref
12. Proubasta IR, De Frutos AG, Salo GB, Itarte JP, Ceres EP. Sauvé'-Kapandji procedure using the herbert canulated bone screw. Tech Hand Up Extrem Surg 2000;4(2):120-6. Crossref

13. Kapandji Al. Technique and indications of the KapandjiSauvé procedure in non-rheumatoid diseases of the wrist. In: Nakamura R, Linscheid RL, Miura T, editors. Wrist disorders. Current concepts and challenges. Tokyo: Springer-Verlag; 1992. p.275-84. Crossref

14. Lamey DM, Fernandez DL. Results of the modified Sauvé Kapandji procedure in the treatment of chronic posttraumatic derangement of the distal radioulnar joint. J Bone Joint Surg Am 1998;80(12):1758-69. Crossref

15. Darrach W. Partial excision of lower shaft of ulna for deformity following Colles's fracture 1913. Clin Orthop Relat Res 1992;(275):3-4. Crossref

16. Tulipan DJ, Eaton RG, Eberhart RE. The Darrach procedure defended: technique redefined and long-term follow-up. J Hand Surg Am 1991;16(3):438-44. Crossref

17. Grawe B, Heincelman C, Stern P. Functional results of the Darrach procedure: a long-term outcome study. J Hand Surg Am 2012;37(12):2475-80. Crossref

18. Jochen-Frederick $H$, Pouyan $Y$, Khosrow BA, Christoph $\mathrm{H}$, Berthold B, Ulrich K, Thomas K. Long-term functional outcome and patient satisfaction after ulnar head resection. J Plast Reconstr Aesthet Surg 2016;69(10):1417-23. Crossref

19. Adams BD, Leversedge FJ. Distal radioulnar joint. In: Wolfe SW, Pederson WC, Kozin SH, Cohen M, editors. Green's Operative Hand Surgery, 7th ed. Chicago: Elsevier; 2016. p.479-515.

20. Schiffman B, Hanel D. The one bone forearm. Hand Clin 2020;36(4):531-38. Crossref

21. Kim SY, Chim H, Bishop AT, Shin AY. Complications and outcomes of one-bone forearm Reconstruction. Hand (N Y) 2017;12(2):140-4. Crossref

22. Devendra A, Velmurugesan PS, Dheenadhayalan J, Venkatramani H, Sabapathy SR, Rajasekaran S. One-bone forearm reconstruction: A salvage solution for the forearm with massive bone loss. J Bone Joint Surg Am 2019;7;101(15): e74. Crossref

23. Solla F, Lemoine J, Musoff C, Bertoncelli C, Rampal V. Surgical treatment of congenital pseudarthrosis of the forearm: Review and quantitative analysis of individual patient data. Hand Surg Rehabil 2019;38(4):233-241. Crossref 